\title{
Measuring energy efficiency - structural and index decomposition analysis
}

\author{
Paulina STACHURA \\ University of Warsaw, Poland
}

\begin{abstract}
Aim: The aim is to recognize the main determinants of the energy efficiency improvement in transport in Poland in the years 2000-2014 using structural and index decomposition analysis, and to identify areas where there is still potential for further reduction of energy consumption.
\end{abstract}

Design / Research methods: Techniques used to analyse changes in energy use are: structural decomposition analysis and index decomposition analysis. Each of these two methods is characterized by distinctive, unique techniques and approaches, as they have developed quite independently. Index decomposition analysis measures the impact of energy efficiency gains on the level of energy consumption, at the most detailed sector disaggregation level allowed by the available data. Whereas structural decomposition analysis allows to analyse the impact of the external factors, such as technological, demand, and demographic effects, on the fluctuations of the total energy consumption. The similarities and differences between the two approaches are summarized and illustrated with a numerical example of Polish transport.

Conclusions / findings: The article recognizes the main determinants of the energy efficiency improvement in transport sector in Poland in the years 2000-2014. In case of Poland ODEX shows an overall progress of energy efficiency in transport by $24.3 \%$. Results obtained with decomposition analysis indicate large divergences in energy efficiency improvements between modes of transport and vehicle types and identify areas where there is still potential for further reduction of energy consumption. Results from decomposing structure of energy use, show activity effect to be main reason for energy use growth. The distribution of each mode in total traffic of passengers and goods changes toward less energy efficient modes. The only factor driving down the energy use is energy savings.

Originality / value of the article: Using two methods of decomposition analysis and comparing obtained outcomes allows to get a broader view on energy use trends. Results presented in this article are a good starting point for further detailed analysis of changes in energy use of transport.

Keywords: energy efficiency, index decomposition analysis, structural decomposition analysis, indicators, energy

JEL: O13, Q40, Q56

Contact details: Paulina Stachura, Faculty of Economic Sciences, University of Warsaw, Dluga str. 44/50, 00-241 Warsaw, Poland, pstachura@ wne.uw.edu.pl.

Received: 15.10.2017, 02.04.2018, Revised: 19.04.2018, Accepted: 21.05.2018

DOI: http://dx.doi.org/10.29015/cerem.510 


\section{Introduction}

European environmental policy has evolved since the 1990s, due to energy security and climate change concerns, and now focuses on five dimensions: energy security, the internal energy market, energy efficiency, decarbonisation of the economy, as well as research, innovation, and competitiveness. In order to advance energy efficiency improvement, changes in law and new regulations were introduced at the international and national levels. While also putting obligation on the governments to report on the progress. The current 2030 target on $27 \%$ energy efficiency improvement (from 1990 levels) is accompanied by a $40 \%$ greenhouse gas emissions (GHG) reductions target and a $27 \%$ target for renewable energy in each Member State. Implementation of the new energy policy and the increasing number of energy targets induces an urgent need to understand the trends in energy use and select appropriate tools for monitoring progress. The purpose of the indicators is to assess the results achieved, the extent to which the objectives have been met, while enabling international benchmarking.

One of the main focuses of the vast literature has been on identifying drivers for changes in total energy use (Ang, Zhang 2000; Liu, Ang 2007). Decomposition analysis has become useful tool for comparing the driving forces of change in energy use of the whole economy and main sectors (Weber 2009). In general, there are many reasons why country's energy demand changes over time, e.g. growth in economic output, investment in infrastructure, efficiency improvements or changes in the production and consumption patterns. Decomposition analysis attempts to divide changes in energy consumption over time into various driving forces for change. It aims to distinct between energy efficiency increases representing energy savings or "technical changes" and other factors like changes in the structure of an economy, demographic or behavioural changes etc. (Metcalf 2008).

There are two well-developed schools of decomposition studies, the methods of index decomposition analysis and structural decomposition analysis (Hoekstra, van der Bergh 2003; Ang, Zhang 2000). Each of these two methods is characterized by distinctive, unique techniques and approaches, as they have developed quite independently. An index decomposition analysis measures the impact of energy 
efficiency gains on the level of energy consumption at very detailed sector disaggregation level (by sub-sector or end-use). While structural decomposition analysis allows to analyse the impact of the external factors, such as technological, demand, structural and demographic effects, on the fluctuations of the total energy use.

In this article, the energy usage indicators are compared and analysed for transport sector in Poland in the years 2000-2014. The aim is to identify factors determining changes in energy consumption in this sector using structural and index decomposition analysis. The similarities and differences between the two approaches are also summarized and illustrated. The study was conducted on the basis of data provided for this purpose by Enerdata, the data controller of the EU ODYSSEE-MURE program in which engages 28 EU Member States and Norway. The program has been developed to monitor indicative energy policy targets introduced in European Union by Directive 2006/32/EC. It aims at continuous monitoring of changes in energy consumption. It employs two complementary ODYSSEE databases: one for energy efficiency and second for $\mathrm{CO}_{2}$ emissions, as well as MURE database for policy enforcement measures to reduce energy consumption.

\section{Index decomposition analysis}

The term index decomposition analysis was first used in Ang and Zhang (2000) to differentiate the technique from structural decomposition analysis. Index decomposition analysis is methodologically based on tools used for analysing energy-related trends since the $1970 \mathrm{~s}^{1}$, first used to study the impact of changes in product mix on industrial energy demand. It has since been expanded to include other areas including $\mathrm{CO}_{2}$ emission analysis, environmental management, and sustainable use of natural resources. An aggregated component, for example the energy consumption of one sector, is broken down into several determining factors

\footnotetext{
1 The use of index decomposition analysis in order to describe and analyse trends in energy consumption started in the 2nd half of the 1970s in the U.S. (Weber 2009).
} 
to analyse their influence on the aggregate. In this section index decomposition analysis of the energy demand variation is carried out for transport sector in Poland to show the drivers behind the changes observed. The analysis was based on unit consumption data used to calculate the energy efficiency index of Polish economy in the ODYSSEE-MURE program.

The Odyssee energy efficiency index (ODEX) is the leading indicator used in the ODYSSEE-MURE program and published by the European Environmental Agency (EEA) to verify progress on energy efficiency in Europe. ODEX measures energy efficiency progress of the whole economy (all final consumers) as well as by the main sectors (industry, transport, households) in $28 \mathrm{EU}$ Member States and Norway. ODEX is a bottom-up index, because it is constructed from specific energy consumptions or unit consumptions at the most detailed sector disaggregation level allowed by the available data and re-aggregated at the level of final energy consumption. An aggregated bottom-up energy efficiency indicator is very useful tool for detailed diagnosis by sub-sector or end-use and to evaluate the impact of particular policy measures on energy efficiency improvement (Bosseboeuf et al. 2005).

The ODEX is calculated for three main sectors, i.e. industry, transport and households, as a weighted average of sub-sectoral indices, where the weight is the share in the final energy consumption of each sub-sector. The sub-sectoral indices are calculated from changes observed in unit energy consumption measured in physical units (for instance tons of steel, $\mathrm{m}^{2}$ for dwellings, etc.) and are afterwards aggregated and weighted. Undoubtedly, the value of the energy efficiency index will depend on the degree of sector disaggregation. The greater the disaggregation, the more structural effects will be removed from the indicator. Using indices enables different units to be combined for a given sector. Moreover, since the ODEX is calculated at the sectoral level and mostly based on physical instead of monetary activities, it seems to be a more adequate indicator to estimate energy efficiency trends than energy intensities. In the ODEX methodology the impact of energy efficiency improvement is analytically separated from other factors, like economic growth, structural changes within a sector or weather conditions (Enerdata 2016).

In the ODYSSEE-MURE database the ODEX index is represented by 
percentage change compared to 1990 levels, so it does not focus on absolute values, but shows only the change comparing to the state at the reference year (value of ODEX equal to 99 means a $1 \%$ energy efficiency gain). However, the calculation is based on a sliding base year, which means that energy efficiency gains are measured in relation to the previous year. ODEX cumulates the incremental energy savings from one year to the other (for a detailed description of the methodology see ODYSSEE 2016; Lapillonne, Pollier 2011).

In fact, ODEX is equal to a rate of energy savings, i.e. the ratio between the actual energy consumption of the sector or economy in year $t$ and actual energy consumption without energy savings (Enerdata 2016). In the formula below $I_{t}$ is a value of index for year $t$, then the ratio $I_{t} / I_{t-1}$ is described as the energy consumption of year $t$ divided by the energy consumption that would have taken place in year $t$ had the unit consumptions been those of year $t-1$ (ODYSSEE 2016):

$$
\frac{I_{t}}{I_{t-1}}=\frac{\sum_{i} E C_{i, t}}{\sum_{i} A_{i, t} \cdot U C_{i, t-1}}
$$

where:

i - sector;

$\mathrm{EC}_{\mathrm{i}, \mathrm{t}}$ - energy consumption of sector $i$ in year $t$;

$\mathrm{A}_{\mathrm{i}, \mathrm{t}}$ - activity variable of sector $i$ in year $t$;

$\mathrm{UC}_{\mathrm{i}, \mathrm{t}-1}$ - unit consumption of sector $i$ in year $t-1$.

For the purpose of presented analysis, the ODEX index has been recalculated and represented by percentage change compared to 2000 levels. According to the ODEX indicator (Figure 1) energy efficiency of Polish economy improved by $26.4 \%$ between 2000 and 2014, at an annual average rate of $1.9 \%$ per year. All sectors contributed to the improvement, with the largest gains registered in the industry sector. ODEX for transport until 2011 has been falling very slowly and only in recent years has shown a higher rate of decline. Finally, the index decreasing by an average of $1.7 \%$ per year, reached a value of 75.7 in year 2014 . 


\section{Figure 1. Energy efficiency index ODEX for Poland (2000-2014)}

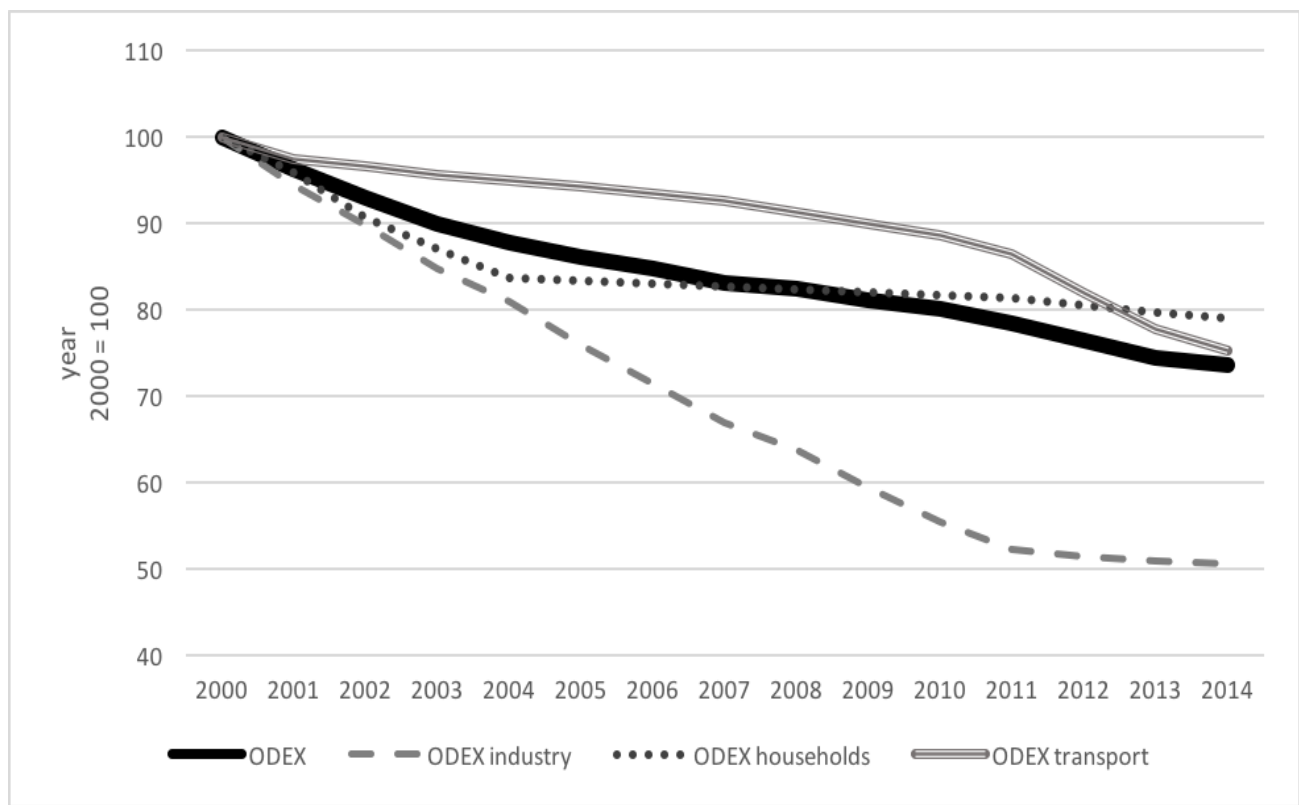

Source: Author's own elaboration based on ODYSSEE databases, ENERA $(2000=100)$.

Methodology of the ODEX allows to calculate the aggregated energy efficiency index in several steps, each with a different level of aggregation. Therefore, it is possible to calculate separate indexes for industry, transport and households, and afterwards, based on these indexes, a general index for all these sectors combined. Also, it is possible to conduct a decomposition analysis of the sector indicator and examine at very detailed level the reasons behind the change.

The results of the decomposition analysis of the ODEX index for transport sector are presented on Figure 2 below. For transport sector, the evaluation is carried out at the level of 3 modes and 4 vehicle types: cars, trucks and light vehicles, motorcycles, buses, air transport, rail, and water transport. For cars and motorcycles, energy efficiency is measured by the specific energy consumption per vehicle. For the transport of goods, the unit consumption per ton-kilometre is used (equal to the transportation of one metric ton of freight one kilometre). Similarly, for the transport of passengers, the unit consumption per passenger-kilometre is used (ODYSSEE 2016). On the basis of the unit consumption data for the individual subsectors, 
included in the sectoral ODEX, trends in energy consumption were computed using the year 2000 as the baseline.

\section{Figure 2. Decomposition of energy use in transport in Poland (2000-2014)}

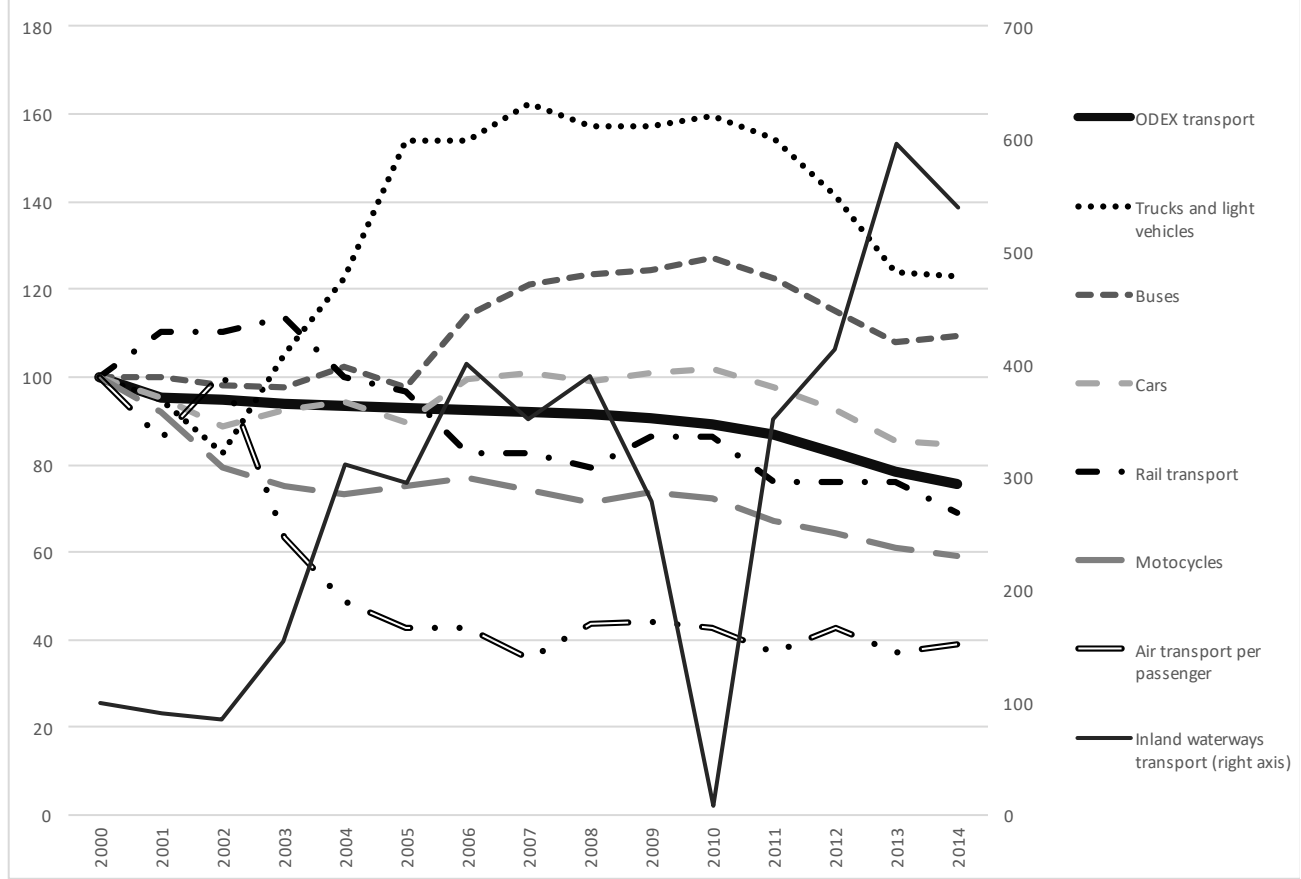

Source: Author's own elaboration based on ODYSSEE databases, ENERA $(2000=100)$.

As shown on Figure 3, energy efficiency of the whole sector increased by $24.3 \%$ between year 2000 and 2014, with an annual average rate of $1.73 \%$. The biggest drop in energy use exceeding $60 \%$ was recorded in air transport. The biggest increase observed was in case of water transport - by $438.5 \%$ (relative to base year). The very large fluctuations in energy consumption in water transport are difficult to understand and may suggest imperfection of statistics, as energy efficiency progress should change smoothly.

Energy efficiency of passenger cars improved by nearly $16 \%$ and motorcycles by over $40 \%$. The trend for trucks and buses was different. After the decline in efficiency, small decrease can be observed after year 2012, but both indexes are still by $22.9 \%$ (trucks) and $9.2 \%$ (buses) above the base year. 
Figure 3. Energy savings in transport in Poland (2000-2014)

\begin{tabular}{|l|r|r|r|r|r|}
\hline \multicolumn{1}{|c|}{ Transport mode } & \multicolumn{1}{c|}{$\mathbf{2 0 0 0}$} & \multicolumn{1}{c|}{$\mathbf{2 0 1 4}$} & \multicolumn{1}{c|}{ Change } & \multicolumn{1}{c|}{ Change/year } \\
\hline ODEX transport & $\mathbf{1 0 0}$ & $\mathbf{7 5 , 7}$ & $\mathbf{- 2 4 , 3 \%}$ & $\mathbf{- 1 , 7 3 \%}$ \\
\hline Inland waterways transport & 100 & 538,5 & $438,5 \%$ & $31,32 \%$ \\
\hline Trucks and light vehicles & 100 & 122,9 & $22,9 \%$ & & $1,63 \%$ \\
\hline Passenger transport & 100 & 109,2 & $9,2 \%$ & $0,66 \%$ \\
\hline Cars & 100 & 84,3 & $-15,7 \%$ & $-1,12 \%$ \\
\hline Rail transport & 100 & 69,0 & $-31,0 \%$ & $-2,22 \%$ \\
\hline Motocycles & 100 & 59,2 & $-40,8 \%$ & $-2,92 \%$ \\
\hline Air transport per passenger & 100 & 39,0 & $-61,0 \%$ & $-4,35 \%$ \\
\hline
\end{tabular}

Source: Author's own elaboration based on ODYSSEE databases, ENERA.

As already mentioned, there are many factors which cause changes in the energy use in transport or any sector, but have no connection with the efficiency with which energy is used. These changes may be structural, behavioural or they may result from factors, such as weather or demographic changes. The ODEX indicator described above measures only the impact of energy efficiency gains on the level of total energy consumption, while other factors which influence final energy consumption are omitted. In order to include impact of external factors on the fluctuations of the total energy consumption another tool was created based on the ODYSSEE databases which allows for structural decomposition analysis.

\section{Structural decomposition analysis}

Structural decomposition analysis allows to understand why country's energy demand changes over time, e.g. due to the growth in economic output, investments in infrastructure, efficiency improvements or changes in the production and consumption patterns, as well as estimating the relative share of each of these effects. This tool is based on the environmental input-output analysis and has become a standard method in energy analysis (Hoekstra, van der Bergh 2003).

The objective of the analysis is to decompose the variation of total final energy consumption over a given period of time into various components (e.g. economic growth, lifestyle changes, energy savings) to analyse their influence on the aggregate. In particular, it allows to explain how the variation of the final energy consumption by sector is linked to the energy savings calculated with top-down 
methods. In ODYSSEE structural decomposition methodology energy savings are derived from:

- Energy efficiency index ODEX presented above or;

- The method proposed by the European Commission for Energy Service Directive (ESD) ${ }^{2}$.

This two approaches are in fact very similar. In case of transport sector the definition of energy savings is the same as proposed by ESD calculations. Despite the importance of the measurement of energy savings, there is also a need to monitor the total amount of energy consumed by sector as it will be the main driver of $\mathrm{CO}_{2}$ emissions.

The variation of the energy consumption of transport is decomposed into three main factors (Bosseboeuf et al. 2015):

- Activity effect - change in passenger traffic;

- Energy savings - variation of the energy consumption per passenger kilometre or tonne-km for each mode of transport;

- Modal shift effect - change in the share of each transport modes in the total traffic.

The activity effect is present in the transport sector due to more traffic for passengers and goods. It captures the changes in the value added and measures the impact of the economic activity on the energy consumption. It is calculated for the different modes of transport separately and then summarized. For passengers, it is calculated by multiplying the variation of the traffic measured in passengerkilometre for each mode by the energy consumption per passenger-kilometre at base year. For goods, it is calculated by multiplying the traffic in tonne-kilometre of each mode by the specific energy consumption per tonne-kilometre at base year. As described in Enerdata (2015) the activity effect is calculated as follows:

Activity effect (passenger): $\mathrm{EQT}_{\frac{\mathrm{t}}{\mathrm{t}-1}}=\sum_{\mathrm{i}=0}^{\mathrm{n}}\left(\Delta \mathrm{pkm}_{\mathrm{n}, \frac{\mathrm{t}}{\mathrm{t}-1}} \times \mathrm{CU}_{\mathrm{n}, \mathrm{t}-1}\right)$

Activity effect (goods): $\mathrm{EQT}_{\frac{\mathrm{t}}{\mathrm{t}-1}}=\sum_{\mathrm{i}=0}^{\mathrm{m}}\left(\Delta \mathrm{tkm}_{\mathrm{m}, \frac{\mathrm{t}}{\mathrm{t}-1}} \times \mathrm{CU}_{\mathrm{m}, \mathrm{t}-1}\right)$

2 The Energy Service Directive 2006/32/EC. 
where:

EQT - activity effect;

$\mathrm{CU}$ - energy consumption per passenger or good kilometre by mode;

$\mathrm{n}=$ cars, bus, rail for passengers;

$\mathrm{m}=$ trucks and light vehicles, rail for goods, inland waterways;

pkm - number of passenger kilometre by mode;

tkm - number of ton kilometre for goods by mode.

Energy savings effect is measured by multiplying the variation of the energy consumption per passenger-km or tonne-kilometre of each mode of transport by the number of passenger/goods kilometre ${ }^{3}$ (Enerdata 2015):

Energy savings (passenger): $\operatorname{EST}_{\frac{\mathrm{t}}{\mathrm{t}-1}}=\sum_{\mathrm{i}=0}^{\mathrm{n}}\left(\Delta \mathrm{CU}_{\mathrm{n}, \frac{\mathrm{t}}{\mathrm{t}-1}} \times \mathrm{pkm}_{\mathrm{n}, \mathrm{t}}\right)$

Energy savings (goods): $\mathrm{EST}_{\frac{\mathrm{t}}{\mathrm{t}-1}}=\sum_{\mathrm{i}=0}^{\mathrm{m}}\left(\Delta \mathrm{CU}_{\mathrm{m}, \frac{\mathrm{t}}{\mathrm{t}-1}} \times \mathrm{tkm}_{\mathrm{m}, \mathrm{t}}\right)$

where:

EST - savings effect;

$\mathrm{CU}$ - energy consumption per passenger or good kilometre for all transport mode;

$\mathrm{n}=$ cars, bus, rail for passengers;

$\mathrm{m}=$ trucks and light vehicles, rail for goods, inland waterways;

pkm - number of passenger kilometre by mode;

tkm - number of ton kilometre for goods by mode.

The weighting method has been defined in such a way that the calculation of energy savings is strictly equal to the sum of energy savings by end-use, with energy savings obtained by multiplying the variation in unit energy consumption by an indicator of activity. For instance, energy savings for cars is equal to the variation in $1 / 100 \mathrm{~km}$ per car multiplied by the number of cars.

For cars, energy savings can be split into four effects (Enerdata 2015):

- Change in the efficiency of cars measured in litre $/ 100 \mathrm{~km}$ ("technical

\footnotetext{
3 The methodology proposed by the Commission to calculate energy savings for the monitoring of the ESD in the top-down approach. It differs from the calculation used for the ODEX as the indicator used for cars is litre $/ 100 \mathrm{~km}$ instead of goe $/ \mathrm{pkm}$.
} 
efficiency effect");

- Change in traffic in passenger-km and distance travelled ("activity effect");

- Change in the average car occupancy rate ("occupancy rate effect");

- Change in fuel mix: from gasoline to diesel and from oil products to biofuel, both leading to an increase of the average heat content in toe/litre ("substitution effect").

Modal shift effect measures the impact of changes in the distribution of each mode in total traffic of passengers and goods. It is calculated as a difference between the sum of savings of each mode for passenger and goods respectively and the aggregate savings calculated for passenger or goods as a whole (Enerdata 2015):

Modal shift for passenger as a whole: $\operatorname{MST}_{\frac{\mathrm{t}}{\mathrm{t}-1}}=\mathrm{EST}-\left(\Delta \mathrm{CU}_{\frac{\mathrm{t}}{\mathrm{t}}} \times \mathrm{pkm}_{\mathrm{t}}\right)$

Modal shift for goods as a whole: $\mathrm{MST}_{\frac{\mathrm{t}}{\mathrm{t}-1}}=\mathrm{EST}-\left(\Delta \mathrm{CU}_{\frac{\mathrm{t}}{\mathrm{t}-1}} \times \mathrm{tkm}_{\mathrm{t}}\right)$

where:

MST - modal shift effect;

EST - savings effect;

CU - energy consumption per passenger or good kilometre by mode;

pkm - number of passenger kilometre by mode;

tkm - number of ton kilometre for goods by mode.

Total energy consumption of transport in Poland has almost doubled between year 2000 and 2014, rising from 9.18 to 15.98 Mtoe (Figure 4). The biggest increase by $93.35 \%$ occurred in years $2002-2011$. 


\section{Figure 4. Total consumption of transport in Poland (2000-2014)}

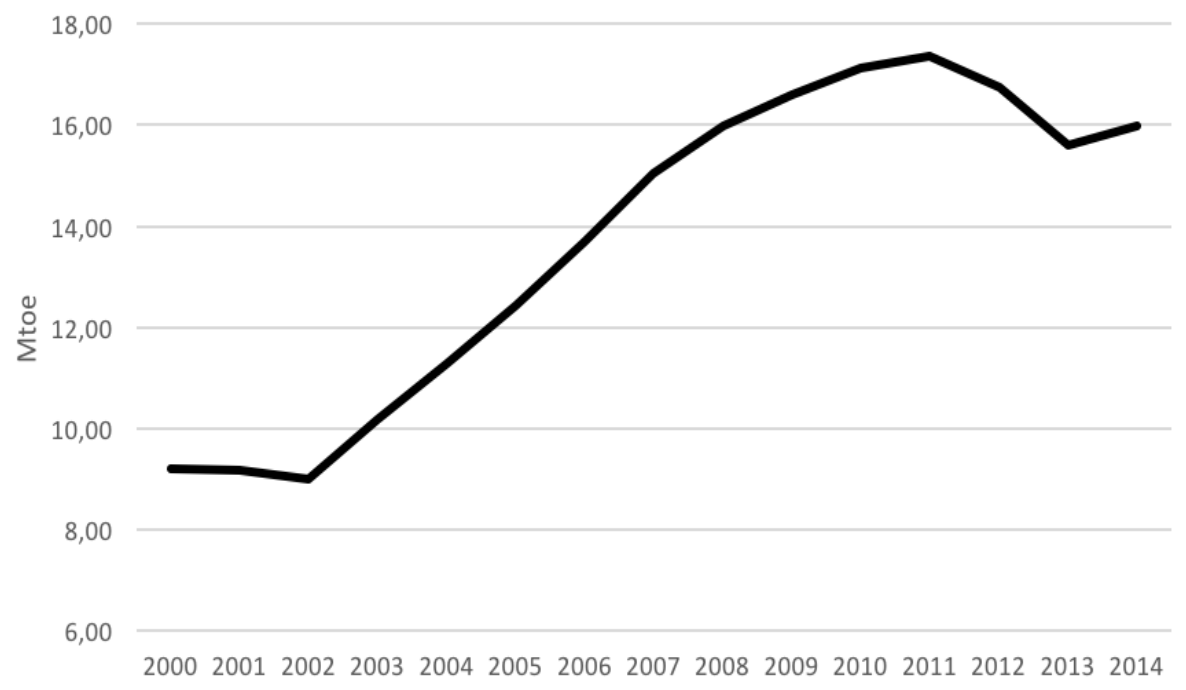

Source: Author's own elaboration based on ODYSSEE databases, ENERA.

The variation of the energy consumption of transport in Poland between year 2000 and 2014 has been decomposed into main factors, as shown on Figure 5. The other effects represent "negative" savings due to inefficient operations in transport. This deterioration of energy efficiency is mainly taking place in freight transport due to low capacity utilization.

As presented on Figure 5, energy consumption of transport has increased by 6.81 Mtoe over the 2000-2014 period mainly due to increase in passenger and goods traffic (activity effect) which contributed to increase of the energy consumption by 8.06 Mtoe. Another positive effect can be noted in modal shift, with increase of 2.73 Mtoe. Whereas, only energy savings decreased the energy consumption by 4.13 Mtoe over the 2000-2014 period. It would be interesting to see, if this structure was more or less constant through analysed period of time and if there are any trends that can be observed and analysed. Figure 6 shows structural decomposition of the annual changes in energy use in transport in Poland in years 2000-2014. 
Figure 5. Structural decomposition of the energy use in transport in Poland (2000-2014)

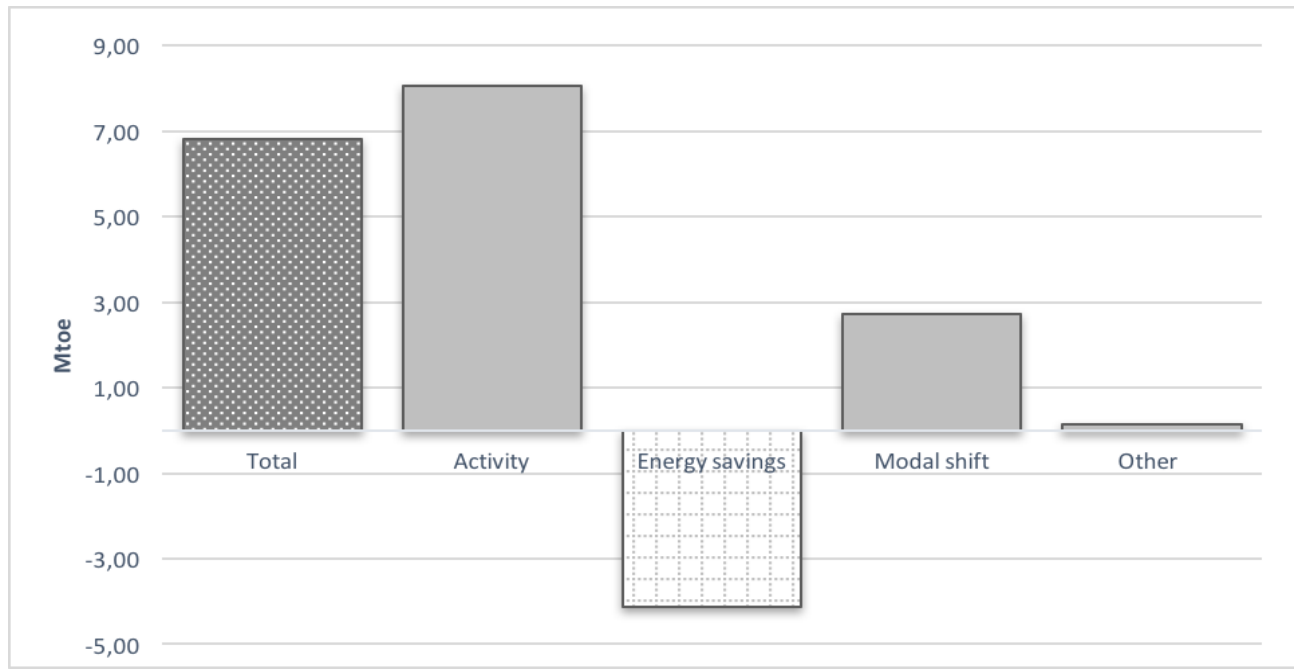

Source: Author's own elaboration based on ODYSSEE databases, ENERA.

Figure 6. Structural decomposition of the annual changes in energy use in transport in Poland (2000-2014)

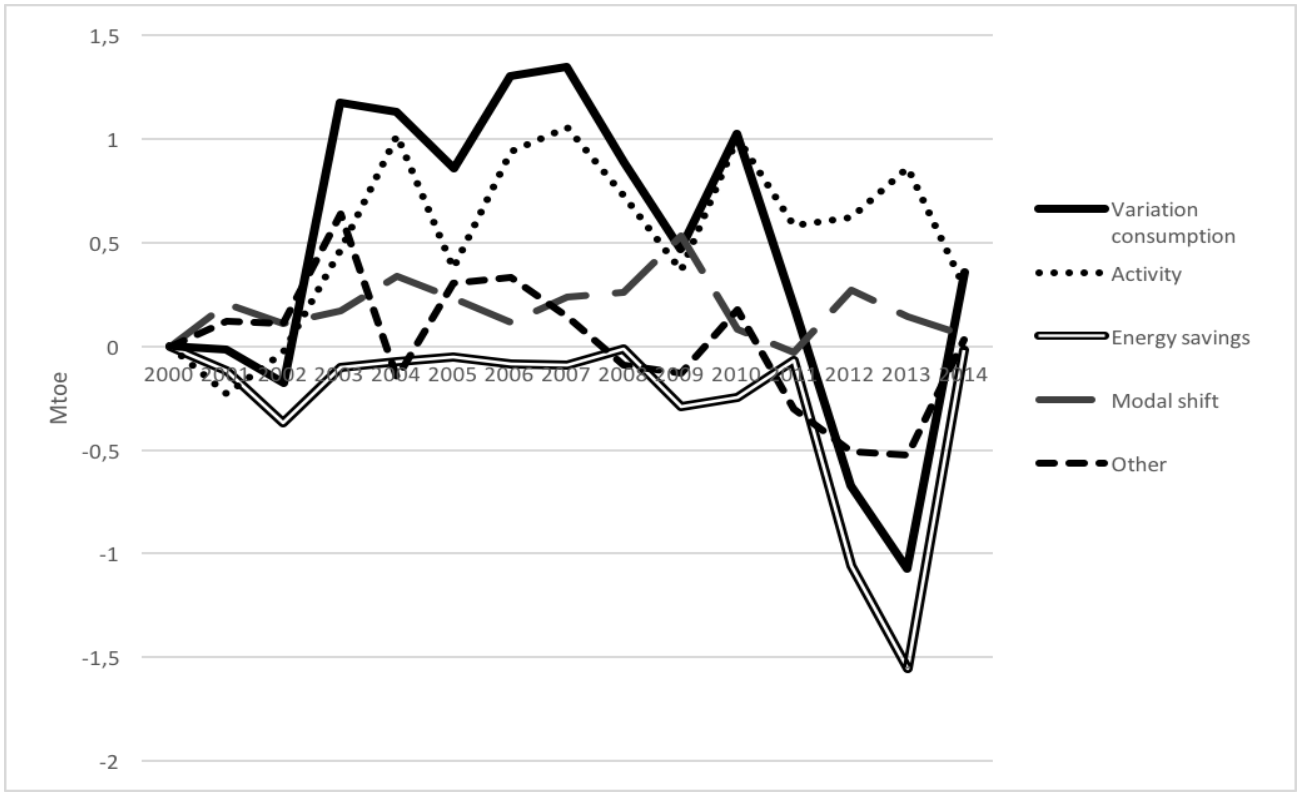

Source: Author's own elaboration based on ODYSSEE databases, ENERA. 
Annual growth of energy use in transport was caused mainly by activity effect, which increased the energy consumption between 0.5 and 1 Mtoe every year. Also, modal shift effect constantly contributed to increase of total energy use in years 2000-2014. The most significant fluctuation concerns energy savings. This effect was almost insignificant through many years and that changed substantially since 2011. Energy savings caused a significant decrease in total energy consumption at the end of analysed period, interrupting the upward trend, what can be observed in Figure 4.

\section{Concluding remarks}

There is a strong political need and demand for monitoring energy efficiency trends, mainly through the use of a limited number of simple, understandable and "saleable" indicators. ODEX is a new type of aggregated energy efficiency index, which is considered to be a very relevant alternative to the popular, but too simplistic energy intensity ratio. ODEX is not only relatively easy to understand by non-specialists, but as an aggregated bottom-up indicator it serves the need of the European Commission for the aggregated indicator to monitor the energy efficiency target fulfilment. On the other hand, it also matches the need for a good proxy of a pure bottom-up evaluation. Moreover, ODEX eliminates structural effects and lifestyle effects as far as possible; and in that sense, it can be concluded that this indicator is closer to an engineering based evaluation of energy efficiency.

This paper recognizes the main determinants of the energy efficiency improvement in transport sector in Poland in the years 2000-2014. This sector includes road, air, rail and water transport. ODEX as an overall energy efficiency index aggregates the trends for each transport mode in a single indicator for the whole sector. Index decomposition analysis consists in breaking down an aggregated component, for example the energy consumption of one sector, into several determining factors to analyse their influence on the aggregate. In case of Poland ODEX shows an overall progress of energy efficiency in transport by $24.3 \%$ between years 2000 and 2014, with an annual average rate of $1.73 \%$. Results 
obtained with decomposition analysis indicate large divergences in energy efficiency improvements between modes of transport and vehicle types and identify areas where there is still potential for further reduction of energy consumption. The biggest drop in energy use exceeding $60 \%$ (relative to base year) was recorded in air transport and the biggest increase by $438.5 \%$ was observed in water transport.

Structural decomposition analysis conducted for transport sector allows to identify driving forces in energy demand over analysed period. Results from decomposing energy usage at the most detailed level possible, show activity effect to be main reason for energy use growth. Energy consumption of transport has increased by 6.81 Mtoe in total and activity effect contributed to the increase of the energy consumption by 8.06 Mtoe in years 2000-2014. The only important factor in driving down the energy use of the transport is energy savings, which decreased the energy consumption by 4.13 Mtoe over the 2000-2014 period. Modal shift effect, with increased by 2.73 Mtoe, proves that the distribution of each mode in total traffic of passengers and goods in Poland changes for worse (i.e. toward less energy efficient modes) and does not support energy use reduction.

To summarize, multiple approaches can be applied to analyse energy use in order to generate a variety of perspectives on determinants of changes. There are two schools of decomposition methods, index and structural decomposition analysis, that can be used to analyse the determinant effects using sector level data, which seem to be complementary. Using these two methods and comparing obtained outcomes allows to get a broader view on energy use trends. Results presented in this paper are a good starting point for further detailed analysis of changes in energy use of transport. 


\section{References}

Ang B.W., Liu N. (2007), Energy decomposition analysis. IEA model versus other methods, „Energy Policy”, vol. 35 no. 3, pp. 1426-1432.

Ang B.W., Zhang F.Q. (2000), A survey of index decomposition analysis in energy and environmental studies, „Energy”, vol. 25 no. 12, pp. 1149-1176.

Bosseboeuf D., Lapillonne B., Eichhammer W. (2005), Measuring energy efficiency progress in the EU. The energy efficiency index ODEX, „ECEEE 2005 Summer Study Proceedings - What works \& who delivers", https://www.eceee.org/library/conference_proceedings/eceee_Summer_Studies/2005/ [02.11.2018].

Bosseboeuf D., Lapillonne B., Pollier K. (2015), Decomposition analysis of the energy demand methodology and ODYSSEE tool, ADEME, Riga.

Enerdata (2015), Understanding variation in energy consumption. Methodological report, http://www.indicators.odyssee-mure.eu/php/odyssee-

decomposition/documents/interpretation-of-the-energy-consumption-variation-glossary.pdf [20.05.2018].

Enerdata (2016), Definition of data and energy efficiency indicators in ODYSSEE data base, http://www.odyssee-mure.eu/publications/other/ [20.05.2018].

European Union (2006), Directive 2006/32/EC of the European Parliament and of the Council of 5 April 2006 on energy end-use efficiency and energy services and repealing Council Directive 93/76/EEC.

Hoekstra R., van den Bergh J. (2003), Comparing structural decomposition analysis and index, „Energy Economics”, vol. 25 no. 1, pp. 39-64.

Lapillonne B., Pollier K. (2011), Decomposition of final and primary energy consumption, Enerdata, Grenoble.

Metcalf G.E. (2008), An empirical analysis of energy intensity and its determinants at the state level, „The Energy Journal”, vol. 29 no. 3, pp. 1-26.

ODYSSEE (2016), Definition of ODEX indicators in ODYSSEE data base, http://www.indicators.odyssee-mure.eu/odex-indicators-database-definition.pdf [20.05.2018].

Weber C. (2009), Measuring structural change and energy use. Decomposition of the US economy from 1997 to 2002, „Energy Policy”, vol. 37 no. 4, pp. 1561-1570. 